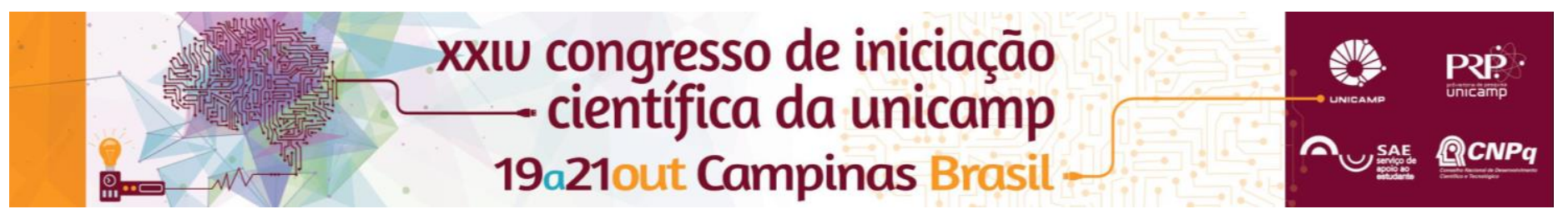

\title{
Repercussão da gagueira na fala e suas implicações nas atividades e participação de adolescentes e adultos gagos
}

\author{
Jéssica Fontoura Bellezo*, Nátali Romano, Regina Yu Shon Chun
}

\section{Resumo}

O objetivo é investigar a repercussão da gagueira na fala e suas implicações nas atividades e participação de adolescentes e adultos com gagueira, tomando a Classificação Internacional de Funcionalidade, Incapacidade e Saúde (CIF) como base conceitual. Foram entrevistados 39 adultos e adolescentes, sendo 19 participantes com gagueira em acompanhamento fonoaudiológico e 20 sem gagueira. Os participantes com gagueira referiram maior impacto da fala em suas atividades diárias e, consequentemente, na qualidade de vida.

\section{Palavras-chave:}

Gagueira, CIF, Fonoaudiologia.

\section{Introdução}

A linguagem possibilita a construção de relações com o outro, exposição de ideias, valores e conhecimentos. $\mathrm{Na}$ presença de alterações de fala podem haver repercussões nas atividades e participação. Definir gagueira como fala com quebras de ritmo, como a CID-10, não contempla possíveis impactos sociais e de interação das pessoas com gagueira. AmClassificação Internacional de Funcionalidade, Incapacidade e Saúde (CIF) possibilita abranger tais questões ${ }^{1}$. O objetivo é investigar a repercussão da gagueira na fala e suas implicações nas atividades e participação na vida de adolescentes e adultos gagos, tomando a CIF como base conceitual.

\section{Resultados e Discussão}

Foram entrevistados 39 participantes, 10 adultos e 10 adolescentes sem gagueira (G1) e 10 adultos e 9 adolescentes com gagueira em acompanhamento fonoaudiológico (G2). Realizou-se coleta de dados por meio de entrevistas com roteiro semi-estruturado utilizando a CIF para análise ${ }^{2}$. Solicitou-se uma narrativa oral para classificação do Perfil de Fluência da Fala (PFF) ${ }^{3}$. Os resultados do PFF estão fora do esperado quanto à frequência de rupturas para dois participantes de G1 e 18 participantes de G2 tiveram a porcentagem de disfluências gagas acima do esperado. Seguem resultados de alguns domínios dos componentes da CIF de funções do corpo, atividades e participação na Tabela 1.

Tabela 1: Qualificadores dos domínios da CIF de funções do corpo, atividades e participação

\begin{tabular}{|c|c|c|c|c|c|c|c|c|c|c|}
\hline \multirow[t]{3}{*}{ Domínios } & \multicolumn{10}{|c|}{ Qualificadores da CIF } \\
\hline & \multicolumn{5}{|c|}{ G1 $(\mathrm{n}$ total $=20)$} & \multicolumn{5}{|c|}{ G2 $(\mathrm{n}$ total $=19)$} \\
\hline & 0 & 1 & 2 & 3 & 4 & 0 & 1 & 2 & 3 & 4 \\
\hline $\begin{array}{l}\text { Fluência e ritmo de } \\
\text { fala (b330) }\end{array}$ & 12 & 7 & 1 & 0 & 0 & 1 & 6 & 9 & 2 & 1 \\
\hline $\begin{array}{l}\text { Tomar decisões } \\
\text { (d177) }\end{array}$ & 11 & 8 & 1 & 0 & 0 & 15 & 2 & 2 & 0 & 0 \\
\hline $\begin{array}{l}\text { Funções } \\
\text { emocionais (b152) }\end{array}$ & 10 & 7 & 3 & 0 & 0 & 2 & 8 & 7 & 2 & 0 \\
\hline $\begin{array}{l}\text { Relacionamentos } \\
\text { sociais informais } \\
\text { (d750) }\end{array}$ & 5 & 11 & 3 & 1 & 0 & 4 & 6 & 5 & 4 & 0 \\
\hline
\end{tabular}

Legenda: 0 - não há problema; 1 - problema ligeiro; 2 - problema moderado; 3 - problema grave; 4 - problema completo.
Os domínios com qualificadores mais prejudicados para G2 relacionam-se ao falar, funções emocionais e relações interpessoais, diferentemente de G1. Resultados similares a outros autores ${ }^{4}$, que abordam a tendência das pessoas com gagueira evitar situações sociais e de fala. Poucos participantes referiram dificuldades com tomada de decisões e lazer.

Em relação aos fatores ambientais (Tabela 2), observouse que amigos e família próxima foram considerados como facilitadores. No entanto, atitudes sociais prevaleceram como barreiras para ambos os grupos. Os fonoaudiólogos (profissionais de saúde) foram considerados como facilitadores por todos os sujeitos com gagueira.

Tabela 2: Qualificadores dos domínios de fatores ambientais.

\begin{tabular}{|l|l|l|l|l|}
\hline Domínios & \multicolumn{2}{|l|}{ Facilitadores } & \multicolumn{2}{l|}{ Barreiras } \\
\hline & G1 & G2 & G1 & G2 \\
\hline Família próxima (e310) & 18 & 15 & 2 & 4 \\
\hline Amigos (e320) & 20 & 15 & 0 & 3 \\
\hline Profissionais de saúde (e355) & 0 & 18 & 0 & 0 \\
\hline Atitudes sociais (e460) & 4 & 2 & 7 & 13 \\
\hline
\end{tabular}

\section{Conclusões}

Os resultados mostram as repercussões da gagueira na fala e as implicações na vida para as pessoas com gagueira (G2), como expresso pelos qualificadores. $O$ grupo de pessoas que se veem e/ou são vistas como gagas referem mais impactos negativos da fala em suas atividades diárias, participação na sociedade e nos ambientes em que transitam, bem como enfrentam mais barreiras nas relações com amigos e familiares, em relação ao grupo de pessoas que não gaguejam.

\footnotetext{
Agradecimentos ao SAE/PIBIC-UNICAMP e aos participantes da pesquisa.

Referências Bibliográficas

1.Yaruss, J. S.; Quesal, R. W. Stuttering and the International Classification of Functioning, Disability and Health (ICF): An update. J. of Com. Disorders. 2004; 37 (1): 35-52.

2. Romano, N; Chun, R.Y.S. CIF e qualidade de vida de adolescentes e adultos gagos. Relatório de atividades de Iniciação Científica PIBIC/CNPQ UNICAMP, 2013

3.Andrade, C.R.F. Perfil de Fluência da Fala: parâmetro comparativo diferenciado por idade para crianças, adolescentes, adultos e idosos. Barueri, SP: Pró-Fono, 2006. Série de Livros Digitais de Pesquisas Financiadas por Agências de Fomento.

4. Bloodstein, O; Ratner N.B. A handbook of stuttering ( $\left.6^{\mathrm{a}} \mathrm{ed}\right)$. New York: Thomson Delmar Learning, 2008.
} 